\title{
Gender Prospective: Routes of Transmission and Care Seeking of HIV among HIV Infected Individuals Attending for CD4 T Cell Count in Kathmandu, Nepal
}

\author{
${ }^{1}$ Bimala Sharma, ${ }^{2}$ Bishnu Raj Tiwari, ${ }^{3}$ Prakash Ghimire, ${ }^{4}$ Sarala Malla \\ ${ }^{1}$ Community Medicine Department, Gandaki Medical College \\ ${ }^{2}$ School of Health and Allied Science, Pokhara University, Nepal \\ ${ }^{3}$ Central Department of Microbiology, Tribhuvan University, Nepal \\ ${ }^{4}$ National Public Health Laboratory, Kathmandu, Nepal
}

\begin{abstract}
Gender may play important role on routes of transmission and care seeking of HIV among HIV infected individuals. The objective of the study was to assess gender difference on routes of transmission and care seeking of HIV among HIV infected individuals attending National Public Health Laboratory in Kathmandu, Nepal for CD4 T cell count. A cross-sectional study was conducted in 1945 HIV infected people attending for CD4 Tcell count from March, 2005 to December 2008. Of total, $65.6 \%$ were males and dominant age group was 20-39 years (78.0\%). Median age of the study population was 30 , of males 31 and of females 29 years. The dominant routes of transmission were injecting drug-use (41.0\%) and commercial sex (36.9\%). Males were more likely to report IDU (60.4\% versus $4.2 \%)$ while females were more likely to report CSW (46\% versus $32 \%)$ as their routes of transmission. Regarding sex with partner, $42.7 \%$ of females and $2.1 \%$ of males had reported the acquisition of the infection through their spouses or regular sex partners. Forty percent participants had attended for CD4 T cell count within 12 months since the diagnosis of HIV. Females had attended earlier than males (44\% versus 37\%) for CD 4 T cell count within one year of diagnosis. More males had CD4 T cell counts $<200 / \mu l(42.3 \%$ versus $34.7 \%)$. The difference on age; routes of transmission, arrival time for CD4 T cell count since the diagnosis of HIV and CD4 T cell count were significant with the sex of participants. Major route of transmission was injecting drug use among males and commercial sex among females. Females were younger, attended earlier for CD4 T cell count and had better immunological status. Gender should be considered in control measures of HIV in Nepal.
\end{abstract}

Key words: Gender prospective, routes of transmission of HIV, care seeking, CD4 T cell count

Corresponding address: Ms. Bimala Sharma, Community Medicine Department, Gandaki Medical College, Kaski, Nepal. E-mail: bimalasharma@gmail.com

\section{INTRODUCTION}

Since the diagnosis of first case of acquired immunodeficiency syndrome (AIDS) in 1988, 20,583 HIV positive cases were reported to National Center for AIDS and STD Control (NCASC) in Nepal as of 15 July 2012. ${ }^{1,2}$ Among them, 64\% were males and 36 were females and the highest proportion was of client of sex workers $(42.6 \%)$ followed by housewives $(25.9 \%)^{2}$ The estimated prevalence of HIV in the adult population in Nepal is $0.33 \% .^{3}$ People who inject drugs, men having sex with other men and female sex workers are considered the key high risk population, and male migrant workers and clients of female sex workers as bridging population for transmitting the HIV. Now, HIV/AIDS epidemic is increasing to low risk population. ${ }^{4}$ It is estimated that high risk group share $58 \%$ of all adult HIV cases and the other $42 \%$ occur in general low risk population. ${ }^{3}$

Transmission of HIV occurs through several routes, such as sexual contact, sharing contaminated needles for injecting drugs, receiving a transfusion of a contaminated blood or blood products, transmission from mother to child and occupational exposure. ${ }^{5}$ Globally, sexual contact is the most common route of HIV transmission, accounting for at least $75 \%$ of HIV infections. ${ }^{6}$
Addressing gender difference is essential to reduce HIV risk and increase access to HIV prevention, care and treatment services for women and men. In an era of effective HIV diagnostic and therapeutic modalities, gender continues to impact access to HIV prevention, diagnosis and treatment. ${ }^{7}$ Gender based information on age, routes of transmission, care seeking of HIV and immunological status is essential to plan HIV/AIDs control program in Nepal.

\section{MATERIALS AND METHODS}

A cross-sectional study was conducted among HIV infected people attending National Public Health Laboratory (NPHL) for CD4 T cell count in Kathmandu, Nepal. NPHL is the largest referral center in country equipped with automated CD4 T cell count facility. Although the facility was located in the capital city, the participants came from various part of the country as CD4 T cell count service was not available in other part of the country until the middle of 2008. Majority of the participants were visiting the facility for the first time to measure their CD4 T cell count. A total 1945 participants were included in the study from March, 2005 to December, 2008. During the period of this study, the national guideline for eligibility to start HAART on the basis of CD4 $\mathrm{T}$ cell count was a count of $<200 / \mu \mathrm{L} .{ }^{8}$ Face to face interview was 
conducted with the participants who agreed to participate in the study voluntarily with structured questionnaire to collect the information on age, and routes of transmission and duration of diagnosis of the disease. Three millilitres of blood from each participant was collected for CD4 T cell count. The CD4 T cell count was performed by FACS counting system. ${ }^{9}$

Data were entered in Microsoft Excel sheet and statistical analysis was performed by STATA (version 12). Chi-square test was used for testing statistical significance between sex and categorical variables and $t$ test between sex and continuous variables. The study was approved from the ethical committee of Tribhuvan University, Kathmandu, Nepal. Permission was taken from NPHL before starting the study. Participation was fully voluntary. Participants were briefly explained about the purpose of the study and assured about the confidentiality of the collected information. An informed verbal consent was obtained from all the volunteers.

\section{RESULTS}

Out of 1945 people infected with HIV, $65.6 \%$ were males, who had a median age of 31(Inter-quartile range: 26-36) years; the other $34.4 \%$ were females, and their median age was 29 (Inter-quartile range: 25-35) years. The median age of the study subject was 30 years (Inter-quartile range: 26$35)$. Mean age of the study population was $29.9(\mathrm{SD} \pm 9.8)$ years, of males $30.7(\mathrm{SD} \pm 9.9)$ and of females $28.6(\mathrm{SD} \pm 9.6)$ years. The predominant age group was $30-39$ years $(42.2 \%)$ followed by $20-29$ years $(36.0 \%)$ and the lowest number of people observed in age group $\geq 50$ years $(2.6 \%)$. About $90 \%$ of infected individuals lie in the age group 20-49 years. The predominant age group of infected males was 30-39 years and that of females was 20-29 years. The difference of age across sex was statistically significant $(p<0.001)$.

Table 1: Age Distribution of people infected with HIV across Sex

\begin{tabular}{|l|r|r|r|}
\hline \multicolumn{1}{|c|}{ Variables } & \multicolumn{1}{c|}{$\begin{array}{c}\text { No. of } \\
\text { Females }\end{array}$} & \multicolumn{1}{c|}{ Total } & p value \\
\hline Participants & $669(34.4 \%)$ & $1945(100 \%)$ & \\
\hline Median Age(Q1-Q3) & $29(25-35)$ & $30(26-35)$ & \\
\hline Mean Age( \pm SD) & $28.6( \pm 9.6)$ & $29.9( \pm 9.8)$ & $<0.001$ \\
\hline Age group in years \\
\hline$\leq 19$ & $58(8.7 \%)$ & $159(8.2 \%)$ & $<0.001$ \\
\hline $20-29$ & $293(43.8 \%)$ & $701(36.0 \%)$ & \\
\hline $30-39$ & $239(35.7 \%)$ & $821(42.2 \%)$ & \\
\hline $40-49$ & $66(9.9 \%)$ & $214(11.0 \%)$ & \\
\hline$\geq 50$ & $13(1.9 \%)$ & $50(2.6 \%)$ & \\
\hline Total & $669(100 \%)$ & $1945(100 \%)$ & \\
\hline
\end{tabular}

Note: Q1 $=25^{\text {th }}$ quartile, $Q 3=75^{\text {th }}$ quartile

Major routes of transmission reported were injecting drug use $(41.0 \%)$ and Commercial Sex Work (36.9\%). However among females, only $4 \%$ acquired the infection through injecting drug use (IUD). The highest, $60.4 \%$ of males had reported that injecting drug use (IUD) was their modes of infection where as the highest, $46.0 \%$ of females mentioned they acquired the infection from commercial sex work (CSW). Regarding sex with partner, $42.7 \%$ of females had acquired the infection through their spouses or regular sex partners however only $2.1 \%$ of males had been transmitted by their wives or regular sex partners. The difference in the routes of transmission among males and females was statistically significant $(\mathrm{P}<0.001)$.

Table 2: Routes of transmission reported by people infected with HIV across Sex

\begin{tabular}{|c|c|c|c|c|}
\hline Routes & No. of Males & $\begin{array}{c}\text { No. of } \\
\text { Females }\end{array}$ & Total & $p$ value \\
\hline $\mathrm{CSW}$ & $409(32.0 \%)$ & $308(46.0 \%)$ & $717(36.9 \%)$ & \multirow{5}{*}{$<0.001$} \\
\hline IDU & $771(60.4 \%)$ & $28(4.2 \%)$ & $799(41.0 \%)$ & \\
\hline $\begin{array}{l}\text { Mother to } \\
\text { child }\end{array}$ & $69(5.4 \%)$ & $48(7.1 \%)$ & $116(6.0 \%)$ & \\
\hline $\begin{array}{l}\text { Sex with } \\
\text { partner }\end{array}$ & $27(2.1 \%)$ & $286(42.7 \%)$ & $313(16.1 \%)$ & \\
\hline Total & $1276(100.0 \%)$ & $669(100.0 \%)$ & $1945100 \%)$ & \\
\hline
\end{tabular}

Of total, 24.0\% participants had attended NPHL for CD4 T cell count within 6 months of diagnosis of their seropositive status whereas $40 \%$ attended within 12 months, $22.5 \%$ came within 13 months to 24 months and $22.8 \%$ had come after 3 years of diagnosis of the infection. Stratified by sex, 479(37.6 $\%$ ) of males and 299 (44.6\%) of females had attended for CD4 T cell count within 12 months. The difference of arrival time for CD4 T cell count since the diagnosis of HIV among males and females was statistically significant $(\mathrm{p}<0.001)$.

Table 3: Arrival time for CD4 T cell count since the diagnosis of HIV across Sex

\begin{tabular}{|l|c|r|r|r|}
\hline \multicolumn{1}{|c|}{ Time } & \multicolumn{1}{c|}{$\begin{array}{c}\text { No. of } \\
\text { Males }\end{array}$} & $\begin{array}{c}\text { No. of } \\
\text { Females }\end{array}$ & Total & p value \\
\hline$\leq 6$ months & $288(22.6 \%)$ & $179(26.7)$ & $467(24.0 \%)$ & $<0.001$ \\
\hline $7-12$ months & $191(15.0 \%)$ & $120(17.9 \%)$ & $311(16.0 \%)$ & \\
\hline $13-24$ months & $273(21.4 \%)$ & $164(24.5)$ & $437(22.5)$ & \\
\hline $25-36$ months & $202(15.8 \%)$ & $84(12.6 \%)$ & $286(14.7 \%)$ & \\
\hline$\geq 37$ months & $322(25.2 \%)$ & $122(18.2 \%)$ & $444(22.8)$ & \\
\hline Total & $1276(100 \%)$ & $669(100 \%)$ & $1945(100 \%)$ & \\
\hline
\end{tabular}

Of total, 39.7\% individuals had CD4 T cell count $<200$ cells/ $\mu 1,26 \%$ individuals had 200-349 cells/ $\mu$ l and $34.3 \%$ had more than 350 cell/ $\mu \mathrm{l}$. The relation between CD4 T cell count and sex was statistically significant. Of total, 7.0 \% of infected individuals were on Highly Active Anti-Retroviral Therapy (HAART). The association between HAART and sex was not significant $(\mathrm{P}>0.05)$. 
Sharma et. al. Gender Prospective: Routes of Transmission and Care Seeking of HIV...... JHAS, 2013, Vol. 3, No. 1 P 1-4

Table 4: CD4 T cell count and treatment of people infected with HIV across Sex

\begin{tabular}{|c|l|c|c|c|}
\hline Variables & No. of Males & $\begin{array}{c}\text { No. of } \\
\text { Females }\end{array}$ & Total & p value \\
\hline $\begin{array}{c}\text { CD4 T cell } \\
\text { count }\end{array}$ & & & & \\
\hline$\leq 199$ & $540(42.3 \%)$ & $232(34.7 \%)$ & $772(39.7 \%)$ & 0.002 \\
\hline $200-349$ & $328(25.7 \%)$ & $179(26.7 \%)$ & $507(26.0 \%)$ & \\
\hline$\geq 350$ & $408(32.0 \%)$ & $258(38.6 \%)$ & $666(34.3 \%)$ & \\
\hline \multicolumn{5}{|c|}{ HAART } \\
\hline Yes & $90(7.0 \%)$ & $47(7.0 \%)$ & $137(7.0 \%)$ & 0.982 \\
\hline No & $1186(93.0 \%)$ & $622(93.0 \%)$ & $1808(93.0 \%)$ & \\
\hline
\end{tabular}

\section{DISCUSSION}

In the study, $65.6 \%$ of the participants were males and $34.4 \%$ females. This finding is similar to the finding observed among cumulative HIV/AIDS cases reported to NCASC. 2,3, 10 In contrasts, a study conducted in Russia by Davidson AS et.al. found that $51 \%$ of infected were women. ${ }^{11}$ The reported HIV cases in females was $19 \%$ in 1997 that reached up to $31 \%$ in 2007, 35\% in 2010 and $36 \%$ in 2012 among the total HIV infected population. The reported number of HIV infection in females was found increasing every year in Nepal. ${ }^{2,3,4,10}$

In the study, predominant age group among males and females was $30-39$ years and 20-29 years respectively. About $90 \%$ of the study population lies in the age group 20-49 years which is economically and sexually active group. Similarly, the highest proportion of infection is estimated in the age group of 25-49 years. ${ }^{3}$ In the study, median age of the participants was 30 , and of males 31 years and of females 29 years and this difference in age was statistically significant. HIV infected females were found to be younger than infected males. In the study by Davidson AS et.al, mean age of respondents was found of 28 years which is very similar to our finding.

In the study, major routes of transmission reported were IDU and CSW. Males were more likely to report IDU while females were more likely to report CSW as their routes of infection. Most diverse finding was found on Sex with Partner that $42.7 \%$ of females and $2.1 \%$ of males had reported the transmission of the infection through their spouses or regular sex partners. Similar finding was found in the study conducted in Russia that males were more likely to report injection (62\% versus $45 \%$ ) while females were more likely to report sexual transmission (45\% versus $32 \%$ ) as their perceived infection route. ${ }^{11}$ The dominant mode of transmission was sexual intercourse in women and intravenous drug-use in men in the study done by Warley E et. al., which is also similar to the study. ${ }^{12}$ As in our study, IDU and CSW were the most predominant mode of transmission. ${ }^{1,2,3,10,13}$ This requires more concentrated efforts to address the issues of IDU and CSW to prevent the transmission to general population as housewives are more susceptible for HIV infections as these groups are victimized by their husbands or regular sex partners especially who belongs to the risky sexual behaviors.

In the study, females are more likely to attend health facility (44.6\% versus $37.6 \%$ ) for CD4 T cell count within 12 months since the diagnosis of HIV. About two-fifth of infected individuals had CD4 T cell count $<200$ cells $/ \mu 1$ and more males had CD4 T cell count $<200$ cells/ $\mu \mathrm{l}(\mathrm{p}<0.001)$. Similar finding was found in the study by Collazos $J$ et.al and by Edathodu J et.al that women had higher CD4 T cell counts. ${ }^{14,15}$

Most of the infected females were either CSW or partner of infected persons. Earlier arrival for CD4 T cell count and better count of CD4 $\mathrm{T}$ cell among females might be due to fact that females those who involved in commercial sex came earlier for diagnosis as they knew they belongs to high risk group and those who were partners of infected persons came earlier as they knew their partners seropositive status. Of total, $7 \%$ of infected were on HAART. According to the National Anti-Retroviral Therapy Guideline of the period during study, $39.7 \%$ were found eligible to start HAART. Since most of the participants had come first time for CD4 T cell count, the infected individuals who were already at the stage to start HAART had not started the treatment.

\section{CONCLUSION}

Most of the males were infected either from injecting drug use or commercial sex and the females either from commercial sex or sex with partners. Females were younger, attended earlier for CD4 $\mathrm{T}$ cell count and had better immunological status. Gender should be considered while planning and implementing HIV/AIDS control measures in Nepal.

\section{ACKNOWLEDGEMENT}

We are thankful to all the volunteers who participated in the study and laboratory staffs of National Public Health Laboratory, Kathmandu, Nepal.

\section{REFERENCES}

1. Gurubacharya VL, Rana T, Subedi BK. Profile of AIDS cases in Nepal. JNMA. 1994; 31:337-39.

2. Government of Nepal. Ministry of Health and Population. National Centre for AIDS and STD Control. Cumulative HIV and AIDS Situation of Nepal. July, 2012.

3. Government of Nepal. Ministry of Health and Population. National Centre for AIDS and STD Control. Cumulative HIV 
and AIDS Situation of Nepal. August, 2011.

4. Karki S. HIV/AIDS Situation in Nepal: Transition to Women. (Master Thesis). Paris, France: Linköping University Sweden Santé; 2008.

5. Shaw GM, Hunter E. HIV transmission. Cold Spring Harb Perspect Med. 2012; 2(11).

6. Royce RA, Sena A, Cates W, Cohen MS. Sexual transmission of HIV. N Engl J Med. 1997; 336:1072-78.

7. Theobald S, Tolhurst R, Squire SB. Gender, equity: new approaches for effective management of communicable diseases. Transactions of the Royal Society of Tropical Medicine and Hyg. 2006; 100:299-304.

8. Government of Nepal. Ministry of Health \& Population. National Centre for AIDS and STD Control (NCASC). National Anti-Retroviral Therapy Guidelines, Kathmandu; 2009.

9. Dickinson B. FACS Count System User's Guide, Manual Part Number 11-10658-04 Rev B 1999.

10. Government of Nepal. Ministry of Health and Population. National Centre for AIDS and STD Control. Cumulative HIV and AIDS Situation of Nepal. Kathmandu; August, 2007.

11. Davidson AS, Zaller N, Dukhovlinova E, Toussova O, Feller E, Heimer R, et.al. Speaking the truth: an analysis of gender differences in serostatus disclosure practices among HIV-infected patients in St Petersburg, Russia. Int J STD AIDS. 2012; 23:685-8.

12. Warley E, Tamayo AN, Desse J, De Luca A, Warley F, Salas M, et.al. Characteristics of HIV infection by sex in a suburban district of Buenos Aires for the periods 1998 to 2002 and 2003 to 2005. Medicina B Aires. 2009; 69:305-10.

13. Ministry of Health and Population. Annual Report, 2009/2010, Department of Health Service. Kathmandu: Ministry of Health and Population, Nepal; 2011:187-208.

14. Collazos J, Asensi V, Cartón JA. Sex differences in the clinical, immunological and virological parameters of HIV-infected patients treated with HAART. AIDS. 2007; 21:835-43.

15. Edathodu J, Ali B, Alrajhi AA.CD4 validation for the World Health Organization classification and clinical staging of HIV/ AIDS in a developing country. Int J Infect Dis. 2009; 13:243-6. 